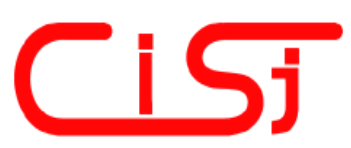

\title{
SYNTHESIS OF ROBUST OPTIMAL CONTROL PROGRAM FOR AXIAL FLOW COMPRESSOR TURNING GUIDE VANES
}

\author{
Kateryna Ugryumova 1), levhen Meniailov ${ }^{2)}$, Iryna Trofymova ${ }^{2)}$, \\ Mykhaylo Ugryumov ${ }^{1)}$, Andriy Myenyaylov ${ }^{3)}$ \\ 1) V.N. Karazin Kharkiv National University, 4 Svobody Sq., Kharkiv, 61022, Ukraine, \\ tps@karazin.ua, ugryumov.mykhaylo52@gmail.com \\ 2) National Aerospace University, 17 Chkalov str., Kharkiv, 61070, Ukraine, \\ evgeniimenyailov@gmail.com, i.trofymova@khai.edu \\ ${ }^{3)}$ Motor Sich Joint-Stock Company, 15 Motorostroiteley Avenue, Zaporizhzhia, 69068, Ukraine, \\ myenyaylov@ukr.net
}

Paper history:

Received 23 February 2019

Received in revised form 11 June 2020

Accepted 08 July 2020

Available online 27 September 2020

Keywords:

stochastic optimization

evolutionary methods;

jet engines;

multistage axial flow compressor;

tolerance selection.

\begin{abstract}
The method of solving the selecting turning guide vanes law of control problem for the multistage axial flow compressor is proposed in order to ensure maximum efficiency along the operating line while maintaining specified stability margins under the uncertainty of input data. The problem under consideration belongs to a class of multi-objective stochastic optimization problems with mixed conditions. Evolutionary computational method of solution synthesis of the problems belonging to this class is developed based on the genetic algorithm. The implementation example of proposed method for selecting law of control for turning inlet at first four stages guide vanes of multistage axial flow compressor (MSAFC) of modern helicopter jet engine is considered. The problem of technological tolerance selecting the stagger angles of compressor blade rows in order to provide the specified confidence intervals based on integral performance parameters is solved. The examples of solving the problem using determined and stochastic formulations are given.
\end{abstract}

Copyright (C) Research Institute for Intelligent Computer Systems, 2020. All rights reserved.

\section{INTRODUCTION}

In the modern world the complex technical systems (CTS) development is characterized by permanent increase in requirements for their power and operating performance. One way to achieve these requirements is to increase accuracy of CTS production. These requirements are particularly actual for modern serial production of CTS and their subsystems. Increase in accuracy of parts manufacturing (or its production tolerances reduction) can be provided by installation of new high-precision equipment allowing to produce the CTS with given parameters. However, new equipment installation always leads to the considerable financial expenses. Thus, the actual technical problem is decreasing development costs of serially produced CTS by choosing rational parameters and corresponding tolerances to serially produced CTS and their subsystem in terms of achieving the integral quality criteria (objective functions) and tolerances on its deviations of CTS overall.

Three types of methods for choosing fits and tolerances are being applied nowadays. These are precedent method (method of analogues), similarity method and calculation method, which are the most reasonable methods for choosing fits and tolerances [1-3]. The existing calculation methods in turn can be divided into a few basic classes: complete interchangeability, fitting, adjusting, group interchangeability (selective assembly), and probabilistic method. In practice, the most perspective are probabilistic methods allowing to find production tolerances for subsystems of complex products which provide specified overall product parameters and also deviation of product parameter not exceeding the specified one without implementing additional operations (and 
consequently without increasing item cost price).

The problem of choosing rational parameters and appropriate tolerances for serially produced CTS and their subsystems are relevant to the problems of CTS system perfection under an uncertainty of input data [4-9]. The analysis of actual literary sources shows that the problems of system perfection of serial CTS (including problems of technological tolerance selection for production of CTS subsystems) adds up to the system optimization problems (decisions making) under an uncertainty of input data. In addition, those in turn can be added up to the sequence of mutually connected multi-objective problems of stochastic optimization (MOPSO). MOPSO of CTS controlled variables that usually have a large dimension are related to the transcomputational problems and require highly informative capacity of resources. The existing MOPSO solution methods usually do not allow finding multiplicity of optimum Pareto's solutions and also do not provide obtaining the result of MOPSO solution with adequate accuracy while using comparatively small informative resources.

Some mathematical problems arise in developing a robust optimal design and intellectual diagnostic methods. These problems involve uncertainty estimation, regularization algorithms structuring and high computational complexity of quasi-solution synthesis methods for practical problems under uncertainties. Today these problems are solved by participants of some scientific programs, for example, EU FP6: NODESIM-CFD [10], EU H2020: UMRIDA [11]. The researches resulted in designing the solution methods for M-problem (a problem of finding the minimum value of objective function expectation), V-problem (a problem of finding the minimum objective function dispersion), P-problem (a problem of finding maximum probability of achieving the given objective function) and stochastic optimization with mixed condition problem solution synthesis and also its realization in design software tools, for example, "Dakota, A Multilevel Parallel Object-Oriented Framework for Design Optimization, Parameter Estimation, Uncertainty Quantification, and Sensitivity Analysis", "IOSO Technology, Robust design optimization" [12, 13], "ESTECO, modeFRONTIER" [14], "Dassault Systems, Isight and Fiper" [15, 16], "DYNARDO, optiSLang" [17], "NUMECA International, FineDesign3D", "Concepts NREC's, Agile Engineering Design System" [18, 19]. These software tools are used for solution of practical problems.

Regarding this the scientific problem of developing mathematical models, methods and computer systems to implement them aimed at system perfection of aeronautical engineering objects under an uncertainty of input data is relevant.

In the paper the method of solving the problem of selecting turning guide vanes law of control for multistage axial flow compressor in order to ensure maximum efficiency along the operating line while maintaining specified stability margin under the uncertainty of input data is presented. The problem under consideration belongs to a class of multiobjective problems of stochastic optimization MOPSO [20]. Evolutionary method for solving MOPSO is developed based on the genetic algorithm $[21,22]$. The implementation example of proposed method for selecting law of control for turning inlet at first four stages guide vanes of multistage axial flow compressor (MSAFC) of TV3-117-VMASBM-1V engine is given. The problem of technological tolerance selecting the stagger angles of compressor guide vanes of TV3-117-VMA-SBM$1 \mathrm{~V}$ engine in order to set the specified confidence intervals based on integral variables of multistage axial flow compressor is solved.

\section{FORMULATION OF THE STOCHASTIC OPTIMIZATION PROBLEM WITH THE MIXED CONDITION}

Stochastic optimization problem is represented in the form $f(x) \rightarrow$ min, where $f$ is the objective function, whose form depends on the conditions of the problem, $x$ is random variable with given distribution. Further the variables $x$ with normal or uniform distribution laws are considered. In case of normal distribution, the variable $x$ can be determined uniquely by specifying its average value $M[x]=x_{c}$ and dispersion $D[x]=\sigma_{x}^{2}$. It should be noted that in case where the optimization problem under consideration is multi-objective, then the variables $x$ and its determining values $x_{c}$ and $\sigma_{x}$ (if $x$ are the independent variables) are vectors with dimensions corresponding to the dimension of current problem.

Because of random nature of $x$ variable, the objective function $f(x)$ also will be a random variable. To present the random objective function we define its mean value $M[f(x)]=f_{c}$ and dispersion $D[f(x)]=\sigma_{f}^{2}$. When defining the probability of the fact that objective function belongs to the specified range at known values of $x_{c}$ and $\sigma_{x}$ in a random manner we form the set of values $X=\left\{x_{1}, x_{2}, \ldots x_{j}, \ldots x_{n}\right\}$ and we compute the corresponding value of objective function 
$f\left(x_{j}\right), j=1 \ldots n$, and define the number of elements $J_{f}$ satisfying the requirement $f_{\min } \leq f\left(x_{j}\right) \leq f_{\max }$.

Then we normalize the obtained value $J_{f}$ by dividing by $n$.

Often, the expression for the objective function contains more than one variable. Let $X^{0}$ be the vector of random variables with dimension $M$ (model parameters, control variables, state variables), $F^{0}$ - vector of random variables with dimension $I$ (measurement data, objective function). The values $F^{0}$ can be found by using the original mathematical model of the research object, that is presented as a $F^{0}=F\left(X^{0}\right)$, where $F$ is vector function.

Let us define projections of $X^{0}$ and $F^{0}$ as random variables with normal distribution by setting their expectations, standard deviation and correlation matrices. Presented input data allows us to present $X^{0}$ and $F^{0}$ by systems of several random variables with multivariate normal distribution.

It should be noted that often in the modification problems at stochastic statement it is necessary to observe the changes of average values and dispersions of objective functions simultaneously and to prevent them from exceeding the given values. Models with mixed conditions are considered for solving this problem. The specified conditions for the multiobjective problem can be entered, for example, as the scalar convolution of objective functions based on Kolmogorov's power averages concept [23].

In accordance with the law of requisite variety (Ashby W.R. law [24]) for a problem-resolution system creation, this system must have a greater variety than the current problem variety or it should be able to create such a variety. Following the Ashby's law, it is obvious that one way to improve the estimation quality is introduction of information redundancy during the process of task solution synthesis by a decision-maker.

It is known that an uncertainty arises under structuring the above-listed tasks in the metrics selection in assessing objective function and unknown values (parameters, control variables or state variables) when the data are random variables.

Thus, regularizing algorithms should be used for solving ill-posed problems of this type. It will provide the stable effective evaluation of unknown quantities, and mathematical models synthesized upon them will have the property of robustness.

According to the power means concept of A.N. Kolmogorov, $t$-Student's statistics will be used for checking criteria of centre distribution equality hypothesis for representative selections from two multivariate populations, and covariance matrices equality hypotheses will be a multivariate analogue of V.I. Romanovsky's criterion $R o$ :

$$
t=\sqrt{\frac{n_{\alpha}}{2} M D^{2}},
$$

where $\mathrm{n}_{\alpha}-$ dimensionality of selections from populations;

$$
M D^{2}=\frac{1}{I}\left(\mathrm{~F}^{\circ}-\left\langle\mathrm{F}^{\circ}\right\rangle\right)^{T} \Sigma^{-1}\left(\mathrm{~F}^{\circ}-\left\langle\mathrm{F}^{\circ}\right\rangle\right),
$$

$\Sigma$ - covariance matrix,

$M D$ - Mahalanobis's distance;

$$
R o=\frac{\left|\chi^{2}-k\right|}{\sqrt{2 k}}, k=n_{\alpha}-2,
$$

where $\chi^{2}=\frac{n_{\alpha}}{N}\left(\sigma^{0}\right)^{T} R \sigma^{0} \quad-\quad$ multivariate analogue of the Pearson's chi-squared test;

$$
\begin{gathered}
N-\text { dimension } X^{0}\left(\text { or } F^{0}\right) ; \\
\sigma^{0}=\left\{\frac{\sigma_{n}}{\sigma_{n}^{*}}\right\}, n=1 . . N ; \\
\sigma_{n}, \sigma_{n}^{*}-\text { standard deviations of variables } \\
x_{n} \in X^{0} \text { (index * - required (desired) values); } \\
R \text { - correlation matrix. }
\end{gathered}
$$

Task of estimation $\hat{X}=\left(M\left[X^{0}\right], \sigma_{X}^{0}\right)$ in this case can be reduced to multi-criteria stochastic optimization problem with mixed condition. According to the maximum probability estimation, the quasi-solution of this problem is following:

$$
\hat{X}=\arg \inf \underset{\hat{X} \in D_{X}}{L}\left(\hat{X} / t_{F}, R o_{F}\right),
$$

where

$$
L\left(\hat{X} / t_{F}, R o_{F}\right)=-\ln \rho\left(t_{X}, R o_{X} / t_{F}, R o_{F}\right)
$$

logarithmic likelihood function, $D_{X}$ - the set of a correctness which is generally defined by a decisionmaker preferences system.

The decision of multi-objective modification problem at stochastic statement is set of Pareto's optimal solutions by objective function model eq. (3). In this case the problem of unique decision selection appears. For selection of unique decision in objective function the additional term is used. This term provides the maximum approximation of the vector problem solution $\hat{X}^{\circ}$ to the prototype vector variables $X^{*}$ under synthesis solution. In that case the objective function takes the form [25]: 


$$
\begin{aligned}
& \hat{f}^{o}=\frac{1}{2 I} \sum_{i=1}^{I}\left\{f_{f i t}\left[4\left(\frac{\Delta_{f_{i}}}{\sigma_{f_{i}}^{*}}\right)^{2}\left(1+\sigma_{f_{i}}^{o}\right)^{-2}\right]+\beta \times f_{f i t}\left(\frac{\left|\chi_{f_{i}}^{2}-k\right|}{\sqrt{2 k}}\right)\right\}+ \\
& +\gamma \frac{1}{2 M} \sum_{m=1}^{M}\left\{f_{f i t}\left[4\left(\frac{\Delta_{x m}}{\sigma_{x m}^{*}}\right)^{2}\left(1+\sigma_{x m}^{o}\right)^{-2}\right]+\beta \times f_{f i t}\left(\frac{\left|\chi_{x m}^{2}-k\right|}{\sqrt{2 k}}\right)\right\} .
\end{aligned}
$$

where $\quad \Delta_{f_{i}}=M_{\alpha}\left[f_{i}\right]-f_{i}^{*}, \quad \sigma_{f_{i}}^{o}=\left\{\frac{\sigma_{f_{i}}}{\sigma_{f_{i}}^{*}}\right\}$, $i=1 . . I ; \chi_{f_{i}}^{2}=n_{\alpha} \frac{M_{\alpha}\left[\left(f_{i}-M_{\alpha}\left[f_{i}\right]\right)^{2}\right]}{\left(\sigma_{f_{i}}^{*}\right)^{2}}$

$$
\Delta_{x m}=M_{\alpha}\left[x_{m}\right]-x_{m}^{*}, \sigma_{x m}^{o}=\left\{\frac{\sigma_{x m}}{\sigma_{m}^{*}}\right\}, m=1 . . M ;
$$

$\chi_{x m}^{2}=n_{\alpha} \frac{M_{\alpha}\left[\left(x_{m}-M_{\alpha}\left[x_{m}\right]\right)^{2}\right]}{\left(\sigma_{m}^{*}\right)^{2}} ;$

$f_{i}^{*}, \sigma_{f_{i}}^{*}$ - mathematical expectation value and standard deviation of variables value $f_{i} \in F^{0}$ (index $*$ - required values);

$x_{m}^{*}, \sigma_{m}^{*}$ - mathematical expectation value and standard deviation value of variable $x_{m}$ for the prototype;

$$
f_{f i t}=1-e^{-C d}, C>1-\text { fitness function; } d,
$$

$d>1$ - fitness function argument; $\beta$ - robustness parameter.

The quasisolution of multi-objective stochastic optimization problem with mixed conditions can be found using regularization method by A.N. Tykhonov.

$$
\hat{X}_{p}^{o}=\arg \inf _{X^{o} \in D_{\mathrm{X}}} \hat{f}^{o}\left(X^{o}, \gamma_{p}\right) .
$$

Choice regularization parameter $\gamma_{p}$ in eq. (5) $\left(\gamma_{p+1}=\gamma_{p} / q, q>1, p=0,1,2, \ldots\right)$ is selected in accordance with the generalized discrepancy principle for nonlinear problems [26].

Each time results of solving the problem (5) $\hat{X}_{p}^{o}, \hat{\mathrm{X}}_{p+1}^{o}$ were examined and the fulfillment of the condition

$$
\| f^{o}\left(\hat{X}_{p}^{o} \|-\mathrm{C}\left(\xi+\mathrm{h}\left\|\Delta \hat{X}_{p+1}^{o}\right\|\right) \geq 0\right.
$$

checked, $C>1$ was verified, where $\xi$ is an error in determining $\left\|f^{*}\right\|, \mathrm{h} \geq \hat{f}^{o}\left(\hat{X}_{p+1}^{o}, \gamma_{p+1}\right) /\left\|\Delta \hat{X}_{p+1}^{o}\right\|$.

If the condition was met, the result subordinate to the request had been chosen as an approximation of the quasi-solution $\left\|f^{o}\left(\hat{X}^{o}\right)\right\| \geq C\left(\xi+h\left\|\Delta \hat{X}^{o}\right\|\right)$. Otherwise the result was chosen from the condition $\left\|f^{o}\left(\hat{X}^{o}\right)\right\| \leq C\left(\xi+h\left\|\Delta \hat{X}^{o}\right\|\right)$.

The problem (5) was solved by evolutional method $[25,27]$.

\section{SOLUTION RESULTS FOR PROBLEM OF SYNTHESIS OF ROBUST OPTIMAL CONTROL PROGRAM FOR MSAFC TURNING GUIDE VANES}

As an example, the solution of law of control definition problem for turning inlet guide vane for first four stages guide vanes of TV3-117-VMASBM-1V engine MSAFC is considered.

Design objectives, mode objectives and characteristics of the prototype are known. The vector $\vec{v}$ is chosen as control variable, whose components are blade stagger angles of inlet guide vane (IGV) and guide vanes (GV) at first stages of MSAFC.

One must take into account that besides finding mathematical expectation of compressor parameter values and their standard deviation it is important to maintain compressor gas-dynamic stability margins with the obtained law of control.

The technique for solving the problem is reported on in the papers [28]. The following laws of controls were examined:

- initial law of control for prototype;

- law of control with independent control of guide vane stagger angles with determinate definition;

- law of control with linear law of dependence between guide vanes stagger angles with stochastic definition.

It is impossible to maintain the selected blade stagger angles absolutely accurate in serial production because of manufacturing tolerances. It may lead to deterioration in the multistage axial- 
flow compressor work.

Assuming the standard deviations of stagger angles of inlet guide vane of first four stages guide vanes of TV3-117-VMA-SBM-1V engine MSAFC is $\sigma_{v}^{*}=0.15$ degrees, the maximum standard deviation of pressure ratio can reach $\sigma_{\pi}=0.34$ which is a large value as a standard efficiency deviation is $\sigma_{\eta} \leq 0.0013$.

In this regard, the problem of selecting the robust optimal control program of MSAFC turning guide vanes with linear law of dependence between stagger angles is stated as MOPSO. The problem is to find control program of MSAFC turning guide vanes - to find mathematical expectation and technological standard deviation values of stagger angle of guide vanes, for which mathematical expectation and standard deviation of integral characteristic along the operating condition line would be equal to desired result with the given stability margin $\Delta K_{s}$ of MSAFC. MSAFC efficiency $\eta_{k}^{*}$ and pressure ratio $\pi_{k}^{*}$ are chosen as integral characteristics. The dependence of $\mathrm{GV}$ stagger angles was chosen as the solution structure presented by following formula $\Delta v_{1}=a_{i}+b_{i}(1-\bar{n})$, where $\Delta v_{i}$ is stagger angle change of $\mathrm{i}$-th $\mathrm{GV} ; a_{i}$ and $b_{i}$ are the parameters of GV law of control, $\bar{n}$ is corrected relative rotational speed of compressor shaft. In the given case to control the blade stagger angles the turning GVs can be actuated by only one control drive.

Interactive computer systems for decisionmaking support (CSDMS) "MS_AFC_ControlLawFinder" for synthesis MOPSO solutions was developed in the SharpDevelop development environment in the C\# programming language. CSDMS is implemented as a standard multi-window (SDI) Windows application.

To perform the one-dimensional calculation of the flow parameters in the axial multistage compressor at a predetermined inlet mass flow rate required not more than $1 \ldots 2$ seconds.

In Fig. 1 and Fig. 2 the laws of control are shown as the dependences of blade stagger angles of GV $\Delta v_{i}$ on relative corrected rotational speed of compressor shaft $\bar{n}$ obtained for different problem statements. The law of control found for stochastic problem statement with mixed conditions provides the change of absolute values of compressor efficiency along the operating line by $0.0034-0.0010$ while relative corrected rotational speed of rotor shaft $\overline{\mathrm{n}}$ changes in the range $0.85 \ldots 1.00$. Stability margins for all MSAFC operating conditions obtained for linear law of control of $\mathrm{GV}$ blade stagger angles in stochastic statement are higher than stability margins obtained for initial law of control.

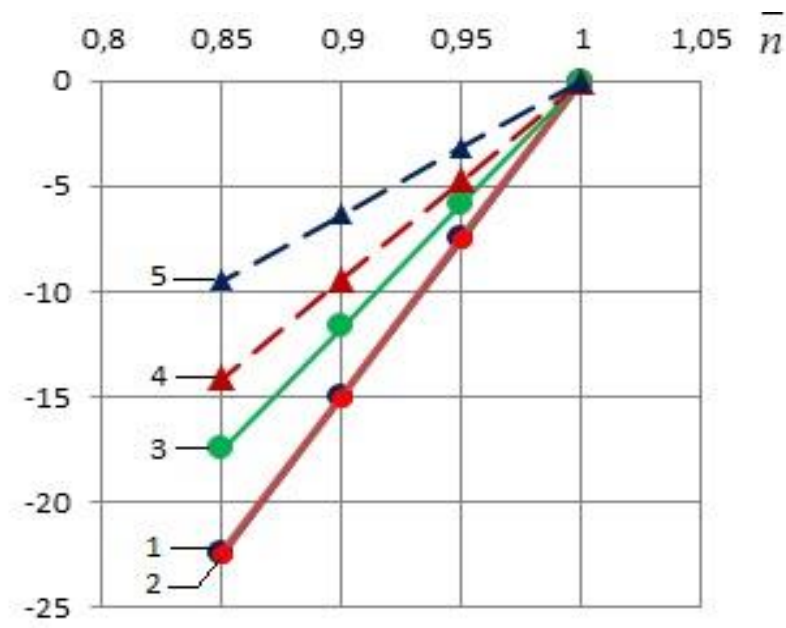

$\Delta v$

Figure 1 - Initial law of control for GV stagger angle (1 - IGV, 2 - first stage GV, 3 - second stage GV, 4 - third stage GV, 5 - fourth stage GV)

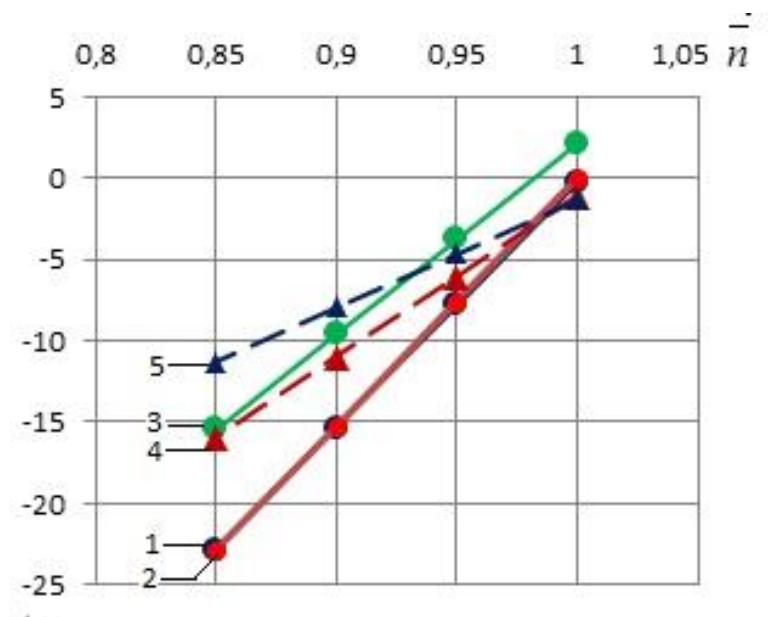

$\Delta v$

Figure 2 - Law of control with linear dependence between GV stagger angles in stochastic problem statement with mixed conditions (1 - IGV, 2 - first stage GV, 3 - second stage GV, 4 - third stage GV, 5 fourth stage GV)

Assuming standard deviation of blade stagger angles of inlet guide vane and guide vanes of the first four stages of multistage axial flow compressor of TV3-117-VMA-SBM-1V engine is $\sigma_{v} \leq 0.050$ degrees for $\bar{n}=[0.85 \ldots 1.00]$ range of modes the following standard deviations of MSAFC integral characteristics $\sigma_{\pi} \leq 0.15$ and $\sigma_{\eta} \leq 0.002$ can be provided with probability of $P^{*}=0.99$.

In Fig. 3 comparison of dependences between the 
standard deviation of the compressor compression ratio $\left(\sigma_{\pi}\right)$ and normalized corrected rotational speed of compressor shaft $(\overline{\mathrm{n}})$ is shown for initial MSAFC turning GV blade stagger angle law of control and one obtained in stochastic problem statement with mixed conditions.

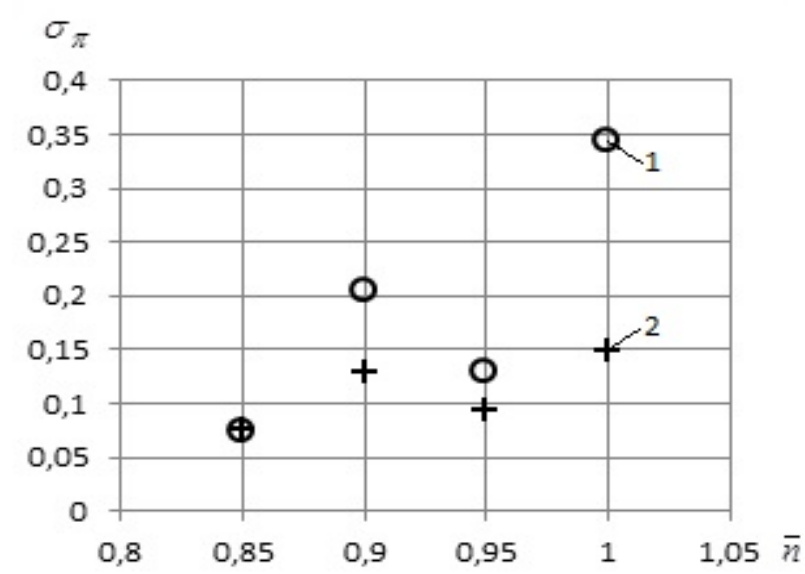

Figure 3 - MSAFC $\sigma_{\pi}$ comparison (1 - initial, 2 obtained from stochastic problem statement with mixed conditions laws of control for variable $\mathbf{G V}$ blades)

It is obvious that the values of MSAFC compression ratio standard deviations obtained as the results of solving the optimization problem under input data uncertainty are lower than standard deviations of MSAFC pressure ratio obtained in determinate statement. Thus, the use of the presented law of control of $\mathrm{GV}$ blade stagger angles of MSAFC reduces the percentage of rejects in serial production and allows avoiding selective assembly of products.

\section{CONCLUSION}

An important practical problem of synthesis of robust optimal control program and standard deviation values of stagger angle for first four stages MSAFC turning guide vanes of TV3-117-VMASBM-1V in order to ensure maximum efficiency along the operating line while maintaining specified stability margin has been solved. The problem under consideration is related to the multi-objective problem class of parametric optimization. The problem solution approach, which means reducing it to the modification problem at deterministic and stochastic statements is proposed. Evolutionary method for solving the assigned problem is developed based on using the genetic algorithm.

Assuming standard deviation of inlet guide vane and guide vanes of first four stages stagger angels of
MSAFC of TV3-117-VMA-SBM-1V engine is $\sigma_{v}=0.050$ for $\bar{n}=[0.85 \ldots 1.00]$ modes the standard deviation of overall MSAFC characteristic $\sigma_{\pi} \leq 0.15, \sigma_{\eta} \leq 0.002$ can be provided with probability $P^{*}=0.99$.

The results obtained by the authors allowed justifying the choice of the high-precision measuring equipment with a certain accuracy class for control of stagger angle of guide vanes during assembly of the compressor.

\section{REFERENCES}

[1] V. I. Anukhin, Fits and Tolerances, tutorial, St. Petersburg, Publishing House of SPbSTU, 2008, 207 p. (in Russian)

[2] V. I. Zakharov, Interchangeability, the Quality of Production and Engineering, St. Petersburg, Lenizdat, 1990, 302 p. (in Russian)

[3] I. Yakushev, L.N. Vorontsov, and N.M. Fedotov, Interchangeability, Standardization and Technical Measurements, textbook, Moscow, Engineering, 1987, 352 p. (in Russian)

[4] A. E. Gelfand, S. K. Ghosh, "Model choice: A minimum posterior predictive loss," Biometrika, vol. 85, issue 1, pp. 1-11, 1998.

[5] A. A. Giunta, M. S. Eldred, L. P. Swiler, T. G. Trucano, and S. F. Wojtkiewicz, "Perspectives on optimization under uncertainty: algorithms and applications," Proceedings of the 10th AIAA/ISSMO Multidisciplinary Analysis and Optimization Conference, Albany, New York, 30 August - 1 September 2004, pp. 1-10.

[6] T. Gneiting, A. E. Raftery, "Strictly proper scoring rules, prediction, and estimation," Journal of the American Statistical Association, vol. 102, no. 477, pp. 359-378, 2007.

[7] T. Erfani, S. V. Utyuzhnikov, "Control of robust design in multiobjective optimization under uncertainties," Structural and Multidisciplinary Optimization, vol. 45, issue 2, pp. 247-256, 2012.

[8] L. Brevault, M. Balesdent, N. Berend, and R. Le Riche, "Multi-level hierarchical MDO formulation with functional coupling satisfaction under uncertainty, application to sounding rocket design," Proceedings of the 11th World Congress on Structural and Multidisciplinary Optimisation, Sydney, Australia, June 7 -12, 2015, pp. 186-205.

[9] S. Lee, D. Rhee, and K. Yee, "Optimal arrangement of the film cooling Holes 
considering the manufacturing tolerance for high pressure turbine nozzle," Proceedings of the ASME Turbo Expo 2016: Turbomachinery Technical Conference and Exposition, Seoul, South Korea, June 13-17, 2016, pp. 793-803.

[10] C. Hirsch, Non-deterministic Simulation for CFD-Based Design Methodologies (NODESIM-CFD), Project co-funded by the European Commission within the Sixth Framework Programme (2002-2006) Project no: AST5-CT-2006-030959/ Publishable summary report D1.1-06, Brussels, Belgium, NUMECA, 2010, $11 \mathrm{p}$.

[11] C. Hirsch, D. Wunsch, J. Szumbarski, L. Laniewski-Wollk, J. Pons-Prats, "Uncertainty management for robust industrial design in aeronautics: Finding and best practice collected during UMRIDA, a Collaborative Research Project (2013-2016) Funded by the European Union," Notes on Numerical Fluid Mechanic and Multidisciplinary Design, Springer, 2019, $818 \mathrm{p}$.

[12] Sigma technology, Robust Design Optimization and Robust Optimal Control, 2018. [Online]. Available at: http://www.iosotech.com/robust. htm

[13] I. N. Egorov, G. V. Kretinin, "Optimization of gas turbine engine elements by probability criteria," Proceedings of the ASME 1993 International Gas Turbine and Aeroengine Congress and Exposition, Cincinnati, Ohio, USA, May 24-27, 1993, pp. 1-8.

[14] Robust design \& reliability, ESTECO's Integration Platform for Multi-objective and Multi-disciplinary Optimization, 2018 [Online]. Available at: http://www.esteco.com/ modefrontier/robust-design-reliability

[15] Isight \& the Simulia Execution Engine, Process Automation and Design Exploration, 2018 [Online]. Available at: http://www.3ds.com/ products-services/simulia/products/isightsimulia-execution-engine/

[16] A. Van der Velden, P. Koch, Insight Design Optimization Methodologies, ASM Handbook, vol. 22B Application of Metal Processing Simulations, Dassault Systèmes, VélizyVillacoublay, France, 2010, 24 p.

[17] Dynamic Software \& Engineering, OptiSLang: Software for Sensitivity Analysis, Multiobjective and Multidisciplinary Optimization, Robustness Evaluation, Reliability Analysis and Robust Design Optimization, 2018ю [Online]. Available at: www.dynardo.de/en/software/optislang.html
[18] NUMECA, FINE TM/Design3D: An Integrated Environment for the Design and Optimization of Turbomachinery Channels and Blades, 2017. [Online]. Available at: http://www.numeca. com/product/finedesign3d

[19] NUMECA Int., "Orientation of NUMECA at innovations in CFD, multiphysics design, analysis and optimization," Leuven, Belgium, issue 3 (62), pp. 71-72, 2014.

[20] Y. M. Ermolev, Methods of Stochastic Programming, Moscow, Nauka, Fizmatgiz, 1976, 240 p. (in Russian)

[21] X.-S. Yang, Cuckoo Search and Firefly Algorithm: Theory and Applications, Springer, New York, 2014, 360 p.

[22] D. Karaboga, S. Okdem, "A simple and global optimization algorithm for engineering problems: Differential evolution algorithm," Turkish Journal of Electrical Engineering, vol. 12, no.1, pp. 53-60, 2004.

[23] S.A. Ayvazyan, Z.I. Bezhaeva, O.V. Staroverov, Multivariate Observation Classification, Moscow, Statistics, 1974, 240 p.

[24] W.R. Ashby, Introduction to Cybernetics, London, Chapman \& Hall, 1956, 295 p.

[25] I. Meniailov, O. Khustochka, K. Ugryumova, S. Chernysh, S. Yepifanov, and M. Ugryumov, "Mathematical models and methods of effective estimation in multi-objective optimization problems under uncertainties," Proceedings of the 12th World Congress of Structural and Multidisciplinary Optimization (WCSMO12), Braunschweig, Germany, June 5-9, 2017, pp. 411-427.

[26] V. Goncharsky, A. S. Leonov, and A. G. Yagola, "Generalized discrepancy principle," Computational Mathematics and Mathematical Physics, issue 2, pp. 294-302, 1973. (in Russian)

[27] M. L. Ugryumov, A. A. Tronchuk, V. E. Afanasjevska, and A.V. Myenyaylov, "Gas turbine engine elements systematic improvement on the base of inverse problem concept by stochastic optimization methods," Abstracts Book and CD-ROM Proceedings of the 20-th ISABE Conference, Gothenburg, Sweden, 2011, article no. 2011-1255.

[28] A. V. Menyailov, A. A, Tronchuk, and E. M. Ugryumova, "Application of evolutionary methods for solving optimization gas turbine compressor," Aerospace Techniques and Technology, issue 5 (52), pp. 59-65, 2008. 


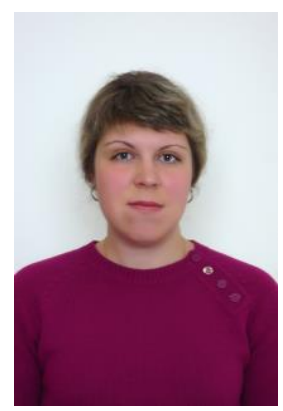

Kateryna M. Ugryumova is $P h D$ in Mathematical Modeling and Computational Methods, Research Scientist of Department of Theoretical \& Applied Systems Engineering Department at Computer Science Faculty of V.N. Karazin Kharkov National University, Master's science. degree in computer.

Her scientific and professional interests are robust optimization design and intellectual diagnostics of gas turbine engine elements, industrial aerodynamics objects; diagnostics of patients in medical monitoring systems; statistical data reduction of testing results; Systems and Methods of Decisions Making.

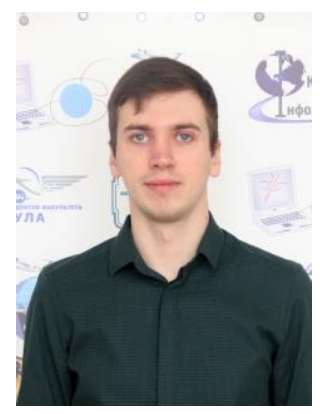

levgen S. Meniailov is $P h D$ student, senior lecturer of Informatics department at National Aerospace University "Kharkiv Aviation Institute". He graduated with honors from the Faculty of Aircraft Control Systems at National Aerospace University "Kharkiv Aviation Institute", the speciality "Applied Mathematics". His fields of scientific activity are mathematical modeling, optimization methods, intelligent systems, decision support systems, software design, programming.

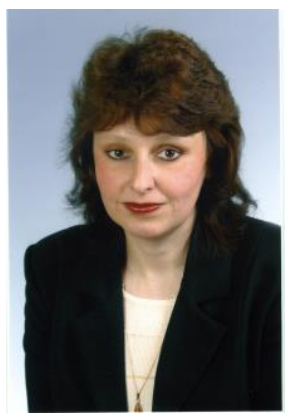

Iryna 0. Trofymova is a Senior Lecturer of the Informatics department at National Aerospace University "Kharkiv Aviation Institute". She graduated from the Faculty of Aircraft Control Systems at National Aerospace University "Kharkiv Aviation Institute". Her scientific and professional interests are mathematical modeling, optimization methods, intelligent systems.

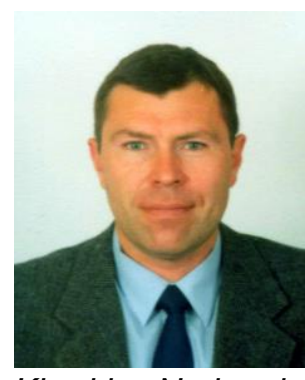

Mykhaylo L. Ugryumov is Full Doctor of Sciences (Technical) Degree in Mathematical Modeling and Computational Methods, Professor of Department of Theoretical \& Applied Systems Engineering Department at Computer Science Faculty of V.N. Karazin Kharkiv National University, ROD\&IDS Software Team Leader, have Academic Status of Senior Research Fellow in in Flying Vehicles Engines and Power Plants. Master of Science degree in Flying Vehicles Engines and Power Plants. His scientific and professional interests are computational fluid dynamics (CFD), finite-difference and finite volume methods, 3D CAE- and design systems using the 3D CFD direct and inverse codes; robust optimization design and intellectual diagnostics of gas turbine engine elements, industrial aerodynamics objects; numerical modeling of $3 D$ atmospheric release, dispersion and explosion of gaseous admixtures (taking into account surface obstacles); experiment's planning and statistical data reduction of testing results; Systems and Methods of Decisions Making.

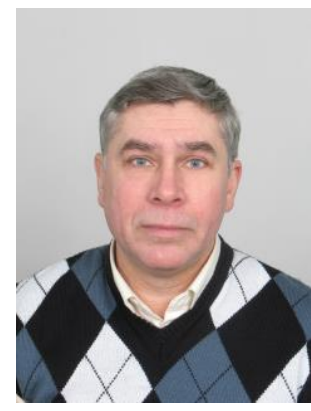

Andriy Myenyaylov is a mechanical engineer. He graduated from National Aerospace University "Kharkiv Aviation Institute" in 1984. PhD on mechanics of fluid, gas and plasma. During 1984-2004 worked at machine-building design department in Zaporozhye on position of engineer, design engineer. Since 2004 worked at Motor Sich JSC as head of computational-experimental group of compressor design department, compressor projecting, compressor testing and testing program development, compressor development to bring in accordance with design targets, compressor as a part of product certification in aerodynamics. At present is working at "AECC CAE" R\&D, China, as special consultant of compressor design. 